\title{
Relationship of umbilical coiling index and perinatal outcome
}

\author{
Shayesta Rahi*, Gulshan Akther \\ Department of Obstetrics and Gynecology, Government Medical College Srinagar, Jammu and Kashmir, India
}

Received: 21 July 2017

Accepted: 18 August 2017

\section{*Correspondence:}

Dr. Shayesta Rahi,

E-mail: drshayesta23@gmail.com

Copyright: $\odot$ the author(s), publisher and licensee Medip Academy. This is an open-access article distributed under the terms of the Creative Commons Attribution Non-Commercial License, which permits unrestricted non-commercial use, distribution, and reproduction in any medium, provided the original work is properly cited.

\section{ABSTRACT}

Background: In placental mammals, the umbilical cord is a conduit between the developing embryo or foetus and the placenta. Present work was done to study the association of umbilical coiling index and perinatal outcome.

Methods: One hundred umbilical cords were examined. The umbilical coiling index was calculated, by dividing the total number of coils by the total length of the cord in centimetres. The umbilical coiling index $<10^{\text {th }}$ percentile and $>90^{\text {th }}$ percentile was considered as hypocoiled and hypercoiled, respectively. The outcomes measured in terms of birth weight, Apgar score, meconium staining, Intrauterine growth restriction, gestational age at birth and Neonatal intensive care unit admission.

Results: The mean umbilical cord length was $51.2 \mathrm{cms}$, mean number of coils 10.8 and mean umbilical coiling index 0.2. 80 umbilical cords showed normocoiling, 10 hypercoiling and 10 had hypocoiling. Meconium stained liquor was present in $80 \%, 37.5 \%$ and $20 \%$ in hypocoiling, normocoiling and hypercoiling group, respectively, with $\mathrm{p}$ valve of $<0.05$. $40 \%$ of babies with hypocoiling cords had Apgar at 1 minute $<4$ and apgar score at 5 minutes $<7$. Intrauterine growth restriction and low birth weight babies were significantly higher in hypercoiling group. Neonatal intensive care unit admission was higher (40\%) in both hypocoiling and hypercoiling group as compared to normocoiling group $(10 \%)$.

Conclusions: Present study thus shows abnormal coiling index is associated with adverse perinatal outcome.

Keywords: Apgar score, Perinatal outcome, Umbilical coiling index

\section{INTRODUCTION}

In placental mammals, the umbilical cord is a conduit between the developing embryo or foetus and the placenta. During prenatal development, the umbilical cord is physiologically and genetically part of foetus and normally contains two arteries and one vein, buried within Wharton's jelly. At term gestation, the normal umbilical cord is $50-60 \mathrm{~cm}$ long and its vessels complete on average 10-11 spirals or coils between the foetal and placental insertion sites. ${ }^{1}$

Umbilical coiling was first quantified in 1954 by Edmonds who divided the total number of coils by the umbilical cord length in centimetres and called it "The Index of twist" assigning positive or negative scores to clockwise or anticlockwise coiling respectively. ${ }^{2}$ Later modifications of his work resulted in the concept of "Umbilical Coiling Index (UCI)" which is calculated by dividing the total number of coils by the total length of the cord immediately after delivery ${ }^{3}$. It has been established that normal umbilical cord coiling is approximately $1 \mathrm{coil} / 5 \mathrm{~cm}$ of umbilical cord length or 0.20 to 0.24 coils $/ \mathrm{cm}^{3-5}$

A coil is of 360-degree spiral course of umbilical vessels. Umbilical cord index (UCI) is defined as the total number of coils divided by the total length of the cord in 
centimetres. A frequency distribution of umbilical cord index (UCI) was done by Rana $\mathrm{J}$ et al. ${ }^{6}$ They grouped the UCI as follows:

- $\quad<10$ th percentile-hypocoiled;

- 10th-90th percentile-normocoiled;

- $\quad$ >90th percentile-hypercoiled

\section{METHODS}

This prospective study was conducted in obstetrics and gynaecology department government Lalla Ded hospital, Srinagar. Pregnant ladies of greater than or equal to 37 weeks of gestation having singleton live baby irrespective of parity and mode of delivery, who were in active labour and admitted in labour room were included in the study. After separating the baby from the umbilical cord, the cord was tied and cut as close to placenta as possible. The umbilical cord was measured in its entirety, including the length of placental end of the cord and the umbilical stump of the baby. The number of complete coils or spirals was counted from the neonatal end towards the placental end of the cord.

The umbilical coiling index was calculated, by dividing the total number of coils by the total length of the cord in centimetres. The centile values of umbilical coiling index were calculated. The umbilical coiling index $<10^{\text {th }}$ percentile and $>90^{\text {th }}$ percentile was considered as hypocoiled and hypercoiled, respectively. The different perinatal factors like birth weight, APGAR score, meconium staining, IUGR, gestational age at birth and NICU admission were studied in relation to UCI.

\section{RESULTS}

In present study, we observed a total of hundred umbilical cords. The mean umbilical cord length was $51.2 \mathrm{cms}$, mean number of coils 10.8 and mean umbilical coiling index 0.2 .

Table 1: Relation of meconium staining with UCI.

\begin{tabular}{|lllll|}
\hline Meconium staining & Hypocoiling & Normocoiling & Hypercoiling & Total P value \\
\hline Present & $8(80 \%)$ & $30(37.5 \%)$ & $2(20 \%)$ & $40(40 \%)$ \\
\hline Absent & $2(20 \%)$ & $50(62.5 \% \%)$ & $8(80 \%)$ & $60(60 \%)$ \\
\hline Total & $10(100 \%)$ & $80(100 \%)$ & $10(100 \%)$ & $100(100 \%)$ \\
\hline
\end{tabular}

Table 2: Relation of Apgar score at I minute with UCI.

\begin{tabular}{|c|c|c|c|c|c|}
\hline Apgar at I minute & Hypocoiling & Normocoiling & Hypercoiling & Total & P value \\
\hline$<4$ & $4(40 \%)$ & $8(10 \%)$ & $2(20 \%)$ & $14(14 \%)$ & \multirow{3}{*}{$<0.05$} \\
\hline$>4$ & $6(60 \%)$ & $72(90 \%)$ & $8(80 \%)$ & $86(86 \%)$ & \\
\hline Total & $10(100 \%)$ & $80(100 \%)$ & $10(100 \%)$ & $100(100 \%)$ & \\
\hline
\end{tabular}

Table 3: Relation of Apgar score at 5 minutes with UCI.

\begin{tabular}{|c|c|c|c|c|c|}
\hline Apgar at 5 minutes & Hypocoiling & Normocoiling & Hypercoiling & Total & P value \\
\hline$<7$ & $4(40 \%)$ & $10(12.5 \%)$ & $2(20 \%)$ & $16(16 \%)$ & \multirow{3}{*}{$<0.05$} \\
\hline$>7$ & $6(60 \%)$ & $70(87.5 \%)$ & $8(80 \%)$ & $84(84 \%)$ & \\
\hline Total & $10(100 \%)$ & $80(100 \%)$ & $10(100 \%)$ & $100(100 \%)$ & \\
\hline
\end{tabular}

Relation of IUGR with UCI.

\begin{tabular}{|lllll|l|}
\hline IUGR & Hypocoiling & Normocoiling & Hypercoiling & Total & P value \\
\hline Present & $2(20 \%)$ & $4(5 \%)$ & $7(70 \%)$ & $13(13 \%)$ & $<0.001$ \\
\hline Absent & $8(80 \%)$ & $76(95 \%)$ & $3(30 \%)$ & $87(87 \%)$ & $100(100 \%)$ \\
\hline Total & $10(100 \%)$ & $80(100 \%)$ & $10(100 \%)$ & $100 \%$ \\
\hline
\end{tabular}

Among the study group 58 were primigravida and 42 were multigravida. 61 delivered vaginally and 39 by LSCS, of which 20 had indication for foetal distress. 80 umbilical cords showed normocoiling, 10 hypercoiling and 10 had hypocoiling. 82 had birth weight $>2.5 \mathrm{kgs}$. Meconium stained liquor was present in 47 patients. Apgar score at 1 minute $<4$ was observed in 18 patients and $>4$ in 82 patients. Apgar score at 5 minutes was $<7$ in
20 cases and $>7$ in 80 cases. In present study, meconium stained liquor was present in $80 \%, 37.5 \%$ and $20 \%$ in hypocoiling, normocoiling and hypercoiling group, respectively, with $\mathrm{p}$ valve of $<0.05$ (Table 1 ). As per Table 2 and 3, 40\% of babies with hypocoiling cords had apgar at 1 minute $<4$ and apgar score at 5 minutes $<7$ and $20 \%$ of babies with hypercoiling cords had apgar at 1 minute $<4$ and apgar score at 5 minutes $<7$. 
Table 5: Relation of birth weight with UCI.

\begin{tabular}{|c|c|c|c|c|c|}
\hline Birth weight & Hypocoiling & Normocoiling & Hypercoiling & Total & $P$ value \\
\hline$<2.5$ & $0(0 \%)$ & $4(5 \%)$ & $6(60 \%)$ & $10(10 \%)$ & \multirow{3}{*}{$<0.001$} \\
\hline$>2.5$ & $10(100 \%)$ & $76(95 \%)$ & $4(40)$ & $90(90 \%)$ & \\
\hline Total & $10(100 \%)$ & $80(100 \%)$ & $10(100 \%)$ & $100(100 \%)$ & \\
\hline
\end{tabular}

Table 6: Relation of NICU admission with UCI.

\begin{tabular}{|c|c|c|c|c|c|}
\hline NICU admission & Hypocoiling & Normocoiling & Hypercoiling & Total & P value \\
\hline Present & $4(40 \%)$ & $10(12.5 \%)$ & $4(40 \%)$ & $18(18 \%)$ & \multirow{3}{*}{$<0.05$} \\
\hline Absent & $6(60 \%)$ & $70(87.5 \%)$ & $6(60 \%)$ & $82(82 \%)$ & \\
\hline Total & $10(100 \%)$ & $80(100 \%)$ & $10(100 \%)$ & $100(100 \%)$ & \\
\hline
\end{tabular}

In normocoiling group, $10 \%$ of babies had apgar at 1 minute $<4$ and $12.5 \%$ had apgar score at 5 minutes $<7$. IUGR and low birth weight babies were significantly higher in hypercoiling group (Table 4 and 5). NICU admission was higher (40\%) in both hypocoiling and hypercoiling group as compared to normocoiling group (10\%) (Table 6).

\section{DISCUSSION}

The umbilical cord is the major fetomaternal unit that provides communication between the placenta and the foetus. However, it is a part of human anatomy and may be prone to compression, tension or torsion, with subsequent interruption of blood flow. It is thought that coiling provides a protective effect to these forces, therefore securing an interrupted blood supply to the foetus. The true etiology of umbilical coiling is unclear, but it is thought to result from foetal movements as well as unequal vascular growth. The umbilical coiling index has been found to be an effective indicator of perinatal outcome. The aim of our study was to find the relationship between UCI and various perinatal factors.

The mean umbilical coiling index of our study was 0.20 which is almost similar to the findings of Ercal $\mathrm{T}$ et al (0.20), Strong TH et al (0.21) and Rana J et al (0.19). ${ }^{3,6,5}$

In present study meconium staining of amniotic fluid was significantly associated with UCI <10th percentile (hypocoiling) with $\mathrm{p}$ value $<0.05$. Similarly, Gupta $\mathrm{S}$ et al, Padmanabhan LD et al and Tripathy $\mathrm{S}$ conducted studies and found that in hypocoiling group, meconium staining was significantly higher than those with normocoiling group..$^{7-9}$

In present study, Apgar score at 1 minute $<4$ and 5 minutes $<7$ was significantly higher in babies with hypocoiled cords. Dakshayini D et al also found that Apgar score at I min $<4$ and $5 \mathrm{~min}<7$ was highly significant $(\mathrm{p}<0.001)$ with hypocoiled cords. ${ }^{10}$ Similarly Gupta $\mathrm{S}$ et al studied 107 cords and found that babies with apgar score $<7$ had significantly lower UCI than the babies with Apgar score $>7$ (p value 0.05$){ }^{7}$
Padmanabhan LD et al. ${ }^{8}$ also found association between Apgar score $<7$ and hypocoiling.

While observing the association of IUGR with UCI, it was found that hypercoiling is strongly associated with intrauterine growth restriction ( $\mathrm{p}$ value $<0.001)$. Ezimokhai $\mathrm{M}$ et al and Chholak D et al obtained similar results in their studies. ${ }^{4,11}$

In present study, $60 \%$ of babies in hypercoiled group had birth weight $<2.5 \mathrm{kgs}$ and none from hypocoiled group had birth weight $<2.5 \mathrm{kgs}$, which was statistically significant ( $p$ value $<0.001$ ). Similar association between hypercoiling and low birth weight was seen in studies conducted by Rana $\mathbf{J}$ et al and Raio L et al. ${ }^{6,12}$

In present study percentage of NICU admission was more $(40 \%)$ in both hypocoiled and hypercoiled groups as compared to normocoiled group. Dakshayini D et al also observed higher NICU admission in both hypocoiled and hypercoiled groups as compared to normocoiled group. ${ }^{10}$

\section{Funding: No funding sources \\ Conflict of interest: None declared \\ Ethical approval: Not required}

\section{REFERENCES}

1. Feyi Waboso PA, Omo-Aghoja LO. Umbilical coiling index in women of South-eastern Nigeria. J Women's health, issues and care. 2014;3:4.

2. Edmonds HW. The spiral twist of the normal umbilical cord in twins and in singletons. Am J Obstet Gynecol. 1954;67:102-120.

3. Strong TH Jr, Jarles DL, Vega Js, Feldman DB. The umblical coiling index. Am J Obstet Gynecol. 1994;170:29-32.

4. Ezimokhai M, Rizk DE, Thomas L. Abnormal vascular coiling of th eumblical cord in gestational diabetes mellitus. Arch Physiol Biochem. 2001;109:209-214.

5. ERcal T, Lacin S, Altunyurt S, Saygili U, Cinal O, Mumcu A. Umblical coiling index: is it a marker for the foetus at risk? Br J Clin Pract. 1996;50:254-6. 
6. Rana J, Ebert GA, Kappy KA. Adverse perinatal outcome in patients with an abnormal umblical coiling index. Obset Gynecol. 1995;85:573-7.

7. Gupta S, Faridi MMa, Krishnan J. Umbilical coiling index. J Obstet Gynecol India. 2006;56:315-9.

8. Padmanabhan LD, Mhaskar R, Mhaskar A. Umbilical vascular coiling and the perinatal outcome. J Obstet Gynecol India. 2001;51:43.

9. Tripathy S. Umbilical Coiling Index and its Relationship with perinatal outcomes. Indian journal of neonatal Medicine and Research. 2014;2(2):1-4.

10. Devaru D, Thusoo M. Umbilical coiling index and perinatal outcome. J Obstet Gynecol India. 2012;62(1):43-46.
11. Chholak D, Gupta P, Khajotia S. Study to evaluate association of umbilical coiling index and perinatal outcome. Int $\mathrm{J}$ reprod Contracept Obstet Gynecol. 2017;6(2):408-412.

12. Raio L, Ghezzi F, Cromi A, Cereda E, Passi A. Sonographic morphology and hyaluronan content of umbilical cords of healthy and down syndrome foetuses in early gestation. Early Hum Dev. 2004;77:1-12.

Cite this article as: Rahi S, Akther G. Relationship of umbilical coiling index and perinatal outcome. Int J Reprod Contracept Obstet Gynecol 2017;6:4433-6. 